\title{
Germinação de aquênios de Lychnophora pinaster em função de estádios de maturação, temperatura e luz
}

\section{Effects of degree of maturation, temperature, and light on the germination of Lychnophora pinaster achenes}

\author{
Paulo Régis Bandeira de MELO ${ }^{1,2}$; João Almir OLIVEIRA ${ }^{3}$; Renato Mendes GUIMARÃES ${ }^{3}$; \\ Carlos Eduardo PEREIRA ${ }^{4}$; José Eduardo Brasil Pereira PINTO ${ }^{3}$ \\ ${ }^{1}$ Parte da dissertação de mestrado do primeiro autor \\ ${ }^{2}$ Dr.; Instituto Federal Sudeste de Minas Gerais; pauloregmelo@yahoo.com.br \\ 3 Dr.; Universidade Federal de Lavras; jalmir@ufla.br; renatomg@ufla.br; jeduardo@dag.ufla.br \\ ${ }^{4}$ Autor para correspondência; Dr.; Prof. Universidade Federal do Amazonas; Instituto de Educação Agricultura e \\ Ambiente; Rua 29 de Agosto, 786, Centro, CEP 69800-000, Humaitá, Amazonas, Brasil; cepereira.ufam@gmail.com
}

Recebido em: 13-06-2013; Aceito em: 29-05-2014

\begin{abstract}
Resumo
A arnica (Lychnophora pinaster Mart.), pertencente à família Asteraceae, é considerada uma espécie medicinal, endêmica de campos rupestres do cerrado e ameaçada de extinção. Neste trabalho, objetivou-se verificar a influência da temperatura e da luz na germinação dos aquênios de arnica colhidos em dois estádios de maturação. Foram utilizados aquênios colhidos nos estádios de maturação: presença e ausência de papus interno. O teste de germinação foi conduzido em mesa termogradiente, nas temperaturas constantes de $15 ; 20 ; 25$ e $30 \pm 2{ }^{\circ} \mathrm{C}$, sob luz contínua e em câmara tipo $\mathrm{BOD}$, à temperatura alternada de $20-30 \stackrel{\circ}{\circ}$, com fotoperíodo de 12 horas, e em ausência de luz. Utilizou-se do delineamento inteiramente casualizado, com distribuição dos tratamentos em esquema fatorial $5 \times 2 \times 2$, com quatro repetições. As avaliações da germinação foram realizadas em dias alternados, por um período total de 60 dias, computando-se ao final a porcentagem e o índice de velocidade de germinação. O estádio de maturação adequado para colheita de frutos e/ou sementes de arnica está relacionado à ausência de papus interno nos aquênios. As sementes de arnica são fotoblásticas positivas preferenciais, onde a incidência de luz afeta positivamente a germinação em temperaturas constantes.
\end{abstract}

Palavras-chave adicionais: arnica; Asteraceae; maturidade; planta medicinal.

\begin{abstract}
Arnica (Lychnophora pinaster Mart.) from the Asteraceae family is a medicinal species, endemic of campo rupestre of cerrado and endangered. This work aimed to study the influence of temperature and light on the germination of achenes of arnica collected in two stages of maturation. We used seeds collected in the stage of presence and absence of internal papus. The germination test was performed in thermogradient table at temperatures $15,20,25$ and $30 \pm 2{ }^{\circ} \mathrm{C}$ under continuous light and incubator (BOD), adjusted at temperatures of 20-30 ${ }^{\circ} \mathrm{C}$ with photoperiod of 12 hours, and without light.

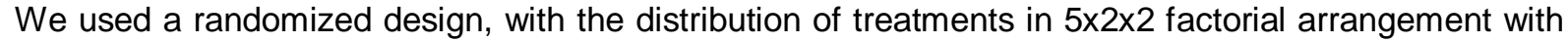
four replications. Evaluations of germination speed and germination percentage were performed in alternate days by a total period of 60 days. The arnica seeds maturation stage for harvest is related to the absence of internal papus. The seeds of arnica are preferred photoblastic positive, where the incidence of light affects positively the germination at constant temperatures.
\end{abstract}

Additional keywords: arnica; Asteraceae; maturity; medicinal plant.

\section{Introdução}

A arnica (Lychnophora pinaster Mart.) é uma espécie da família Asteraceae, encontrada de forma restrita em campos rupestres. Sua reprodução da-se por meio sexuado, cuja floração ocorre entre agosto e outubro, e a dispersão dos frutos, de dezembro a fevereiro (SILVA, 1994). Os aquênios de arnica estão dispostos em subcapítulos de capítulos, apresentando papus internos e externos como estrutura de dispersão (SEMIR, 1991).

A arnica encontra-se com sua perpetuação ameaçada, pois o constante extrativismo, associado às queimadas constantes, tem levado a espécie a enquadrar-se na categoria de plantas vulneráveis (SOCIEDADE BOTÂNICA DO BRASIL, 1992). Na tentativa de reverter esse 
quadro, evitando, assim, uma possível extinção da espécie no futuro, vários esforços estão sendo despendidos (SOUZA et al., 2003; MELO et al., 2007; MELO et al., 2009).

Considerando a necessidade de obtenção de informações científicas sobre seu comportamento em hábitat natural e seus aspectos reprodutivos, SILVA (1994) estudou a espécie quanto aos aspectos da fenologia e reprodução sexuada. SOUZA et al. (2003), utilizando o embrião extraído dos aquênios, desenvolveram um protocolo de propagação in vitro para a arnica. Também, plantas dessa espécie, restritas ao bioma cerrado, podem ser obtidas utilizando-se do solo do seu local de ocorrência para aclimatação das plântulas advindas da cultura de tecido (SOUZA et al., 2004).

Apesar dos avanços na multiplicação da arnica, o aprofundamento dos estudos na propagação sexuada é fundamental como parte integrante de estratégias para futura domesticação da espécie. Além de ser o processo natural de reprodução e apresentar menor custo, a utilização de sementes possibilita a manutenção da variabilidade genética das populações, como ocorre em bancos de germoplasma.

A germinação é um processo biológico, regulado por vários fatores, ocorrendo numa sucessão de eventos fisiológicos. A luz e a temperatura são fatores que influenciam de maneiras distintas sobre a germinação, tendo significado expressivo na evolução e na adaptação ecológica das espécies. Estudos referentes ao efeito da temperatura e do fotoperíodo em sementes de espécies nativas (REGO et al., 2009; BERGO et al., 2010) de cerrado (VELTEN \& GARCIA, 2005) e medicinais (YAMASHITA et al., 2008; AZEVEDO et al., 2010) foram realizados recentemente.

A exigência à luz relaciona-se normalmente a espécies cuja colonização ocorre em áreas abertas (BRYANT, 1989). A classificação das espécies quanto à resposta à luz tem sido dividida em três categorias distintas: fotoblásticas positivas, cujas sementes dependem da luz para promover a germinação; fotoblásticas negativas, que têm a germinação reduzida ou inibida na presença da luz, e não fotoblásticas, que se apresentam indiferentes à presença ou à ausência de luz para germinarem (MARCOS FILHO, 2005). Ainda, segundo KLEIN \& FELIPPE (1991), o caráter fotoblástico positivo pode ser dividido em preferencial, quando ocorre uma porcentagem mínima de germinação das sementes submetidas à ausência de luz, e absoluto, quando não ocorre a germinação na ausência da luz.

Em relação à temperatura, existe uma faixa de maior eficiência, ou seja, em que ocorre a máxima germinação no menor período de tempo (CARVALHO \& NAKAGAWA, 2012).
A temperatura atua na germinação, determinando a capacidade e a porcentagem de germinação das sementes, eliminando as dormências primária e secundária ou induzindo a dormência secundária (BEWLEY \& BLACK, 1994).

Diante do exposto, neste trabalho objetivou-se verificar as exigências de temperatura e de luz na germinação de aquênios de arnica, em dois estádios de maturação, visando a contribuir com informações referentes ao comportamento germinativo desta espécie.

\section{Material e métodos}

A colheita dos aquênios foi realizada em plantas adultas, com tamanho superior a um metro de altura, com auxílio de tesoura de poda, no município de Itumirim-MG - Brasil, no mês de dezembro de 2003. Em seguida, os frutos foram acondicionados em sacos de plástico.

Foram realizadas quatro coletas em dias distintos, sendo as duas primeiras referentes ao estádio cujo papus interno (Figura 1), estrutura de dispersão, apresentava-se aderido aos aquênios presentes nos capítulos (Estádio 1). As coletas subsequentes referiram-se ao estádio em que não havia mais a presença de papus interno, sendo que os aquênios já se encontravam em dispersão (Estádio 2), conforme MELO et al. (2009).

Após a separação manual de aquênios dos capítulos, foi determinado o teor de água das sementes, utilizando-se do método de estufa a $105 \pm 3 \stackrel{\circ}{ } \mathrm{C}$, por 24 horas, conforme as prescrições das Regras para Análise de Sementes (BRASIL, 2009). Foram utilizadas duas amostras de um grama para cada um dos estádios, e os resultados foram expressos em porcentagem. Posteriormente, os capítulos foram submetidos à secagem em estufa de circulação forçada de ar, com temperatura de $27 \pm 3^{\circ} \mathrm{C}$ e umidade relativa do ar média de aproximadamente $60 \%$, por cerca de 72 horas, até que fosse atingido teor de água de $10 \%$ das sementes.

Os capítulos foram debulhados manualmente e, posteriormente, passaram pela pré-limpeza utilizando-se de um protótipo da máquina de ar e peneira. Em seguida, para a finalização do beneficiamento, foi utilizado um soprador vertical modelo South Dakota.

Após o beneficiamento, utilizou-se da técnica de raios $X$ para verificar a porcentagem de aquênios que apresentavam a cavidade embrionária preenchida. Para tanto, os aquênios foram dispostos sobre fita adesiva transparente de dupla face, aderida a uma placa de acrílico transparente, com dimensões de $24 \times 18 \mathrm{~cm}$ e espessura de $2 \mathrm{~mm}$. Após a montagem, a placa com os aquênios foi sobreposta ao filme radiográfico (Kodak $\AA$, Min-R 2000), tamanho $18 \times 24 \mathrm{~cm}$ e submetida à radiação de $30 \mathrm{kv}$, por 
45 segundos, em equipamento de raios $X$ (Faxitron HP®, modelo 43855A X), conforme MELO et al. (2009). Os filmes radiográficos foram revelados e analisados visualmente sobre transiluminador. Foram utilizadas quatro repetições de 50 aquênios.

Para a realização do teste de germinação, os aquênios foram dispostos sobre papel mata-borrão, com umidade de 2,5 vezes a massa do papel seco, e acondicionados em caixas de plástico transparente tipo gerbox $(11 \times 11 \times 3,5 \mathrm{~cm})$, com tampa. Foi utilizado papelalumínio para envolver as caixas nos tratamentos sem luz. O teste foi conduzido em mesa de termogradiente, nas temperaturas constantes de 15; $20 ; 25$ e $30 \pm 2{ }^{\circ} \mathrm{C}$, sob luz contínua e câmara tipo $\mathrm{BOD}$ regulada à temperatura alternada de $20-30 \stackrel{\circ}{\circ}$, com termoperíodo de 12 horas, sob luz contínua, e em ausência de luz.

Foi adotado o critério botânico de emissão da raiz primária (LABOURIAU, 1983) para o cálculo do índice de velocidade de germinação (IVG), utilizando-se da fórmula proposta por MAGUIRE (1962). As avaliações foram realizadas em dias alternados.

Para o teste de germinação, adotou-se a porcentagem de plântulas normais, sendo as mesmas computadas e eliminadas periodicamente até 60 dias após a instalação do teste de germinação. A avaliação da germinação, no tra- tamento sem luz, foi realizada em ambiente reservado sob luz verde (NORONHA et al., 1978).

O delineamento experimental utilizado foi o inteiramente casualizado, com quatro repetições de 100 aquênios, em esquema fatorial $5 \times 2 \times 2$ (sendo cinco temperaturas, dois estádios de maturação e duas condições de luz). Os dados do teste de germinação foram transformados em $\sqrt{x+0,5} \mathrm{e}$, posteriormente, submetidos à análise de variância, utilizando-se do pacote computacional SISVAR (FERREIRA, 2000). As médias foram comparadas pelo teste de Tukey, em nível de $5 \%$ de probabilidade.

\section{Resultados e discussão}

O teor de água, por ocasião da coleta dos aquênios, foi de $30 \%$ para o estádio com papus interno e 14\% para o estádio sem papus interno, sendo que, na montagem do teste de germinação, ambos os estádios encontravamse com teor de água próximo a 10\%.

Houve interação entre temperatura e estádio de maturação, bem como temperatura e luz, para a porcentagem de germinação. Foi também constatada interação entre temperatura e estádio de maturação para o índice de velocidade de germinação (IVG), bem como efeito significativo do fator luz, isoladamente (Tabela 1).

Tabela 1 - Resumo da análise de variância da germinação e do índice de velocidade de germinação (IVG) de aquênios de arnica (Lychnophora pinaster Mart.), em dois estádios de maturação, submetidos a diferentes condições de temperatura e luz. Analysis of variance of germination and germination speed index (IVG) data of arnica (Lychnophora pinaster Mart.) achenes as influenced by achene stage of maturation, temperature and light.

\begin{tabular}{|c|c|c|c|}
\hline \multirow{2}{*}{ Fatores de variação } & \multirow{2}{*}{${ }^{1} \mathrm{GL}$} & \multicolumn{2}{|c|}{ Quadrados médios } \\
\hline & & Germinação & IVG \\
\hline Temperatura & 4 & $2,8734^{*}$ & $0,0119^{*}$ \\
\hline Estádio & 1 & $2,6999^{*}$ & $0,0097^{*}$ \\
\hline Luz & 1 & $19,7250^{*}$ & $0,0593^{*}$ \\
\hline Temperatura $\mathrm{x}$ estádio & 4 & $0,7526^{*}$ & $0,0078^{*}$ \\
\hline Temperatura x luz & 4 & $1,0888^{*}$ & 0,0043 \\
\hline Estádio x luz & 1 & 0,0225 & 0,0025 \\
\hline Temperatura $\mathrm{x}$ estádio $\mathrm{x}$ luz & 4 & 0,2680 & 0,0017 \\
\hline RESÍDUO & 60 & 0,2201 & 0,0018 \\
\hline TOTAL & 79 & - & - \\
\hline CV (\%) & & 29,42 & 5,58 \\
\hline
\end{tabular}

Os aquênios com papus interno submetidos às temperaturas de 30 e $20-30{ }^{\circ} \mathrm{C}$ apresentaram porcentagem de germinação superior quando comparadas à temperatura de $15 \stackrel{\circ}{\circ} \mathrm{C}$ (Tabela 2). Também, para os aquênios mais maduros, sem papus interno, ficou evidenciado que a temperatura de 20-30 ำ possibilitou, significativamente, maior porcentagem de germinação. Grande número de espécies possui uma reação germinativa favorável a uma alternância de temperatura, devido à semelhança do que acontece no ambiente onde se desenvolvem, no qual as temperaturas diurnas são mais altas que as temperaturas noturnas (CARVALHO \& NAKAGAWA, 2012). Segundo RANIERI et al. (2003), diferentes condições para germinação das sementes podem ser reflexo de adaptações ecológicas ao seu ambiente de origem. 
Tabela2 - Porcentagem de germinação e índice de velocidade de germinação (IVG) de aquênios de arnica (Lychnophora pinaster Mart.), em dois estádios de maturação, submetidos a cinco temperaturas, independentemente da luminosidade. Germination percentage and germination speed index of arnica achenes (Lychnophora pinaster Mart.) in two maturation stages and submitted to five temperatures.

\begin{tabular}{|c|c|c|c|c|c|c|}
\hline \multirow{3}{*}{$\begin{array}{c}\text { Temperatura } \\
\left({ }^{\circ} \mathrm{C}\right)\end{array}$} & \multicolumn{2}{|c|}{${ }^{1}$ Germinacão (\%) } & \multicolumn{4}{|c|}{${ }^{1}$ IVG } \\
\hline & \multicolumn{2}{|c|}{ Estádio de maturacão } & \multicolumn{4}{|c|}{ Estádio de maturacão } \\
\hline & Com papus & Sem papus & \multicolumn{2}{|c|}{ Com papus } & \multicolumn{2}{|c|}{ Sem papus } \\
\hline 15 & 0,75 b A & 2,13 b A & 0,0151 & $a A$ & 0,0512 & b A \\
\hline 20 & $1,25 \mathrm{ab} A$ & 2,13 b A & 0,0320 & a A & 0,0568 & b A \\
\hline 25 & $1,75 \mathrm{ab} A$ & 2,38 b A & 0,0899 & a A & 0,0571 & b A \\
\hline 30 & 3,50 a $A$ & 3,00 b A & 0,1009 & a A & 0,0922 & b A \\
\hline $20-30$ & 2,63 a B & 7,88 a $A$ & 0,0626 & $\mathrm{aB}$ & 0,2178 & a $A$ \\
\hline
\end{tabular}

${ }^{\top}$ Médias seguidas da mesma letra, minúscula na coluna e maiúscula na linha, não diferem estatisticamente entre si, pelo teste de Tukey e de F, respectivamente, a $5 \%$ de probabilidade.

Para as temperaturas contínuas, não foi constatada diferença significativa entre os dois estádios de desenvolvimento estudados, enquanto para as temperaturas alternadas de $20-30{ }^{\circ} \mathrm{C}$, os aquênios sem papus interno apresentaram maior porcentagem de germinação (Tabela 2).

De modo semelhante ao observado no teste de germinação, verificou-se que a alternância de temperaturas possibilitou, significativamente, maior índice de velocidade de germinação para os aquênios sem papus interno, assim como maior velocidade de germinação deste tratamento em relação aos aquênios com papus interno submetidos a temperaturas de 20-30 ㅇ (Tabela 2). De acordo com MELO et al. (2009), há maior resposta aos estímulos externos relacionados à germinação, quando os aquênios de arnica estão em estádio mais avançado de maturação, promovendo maior velocidade e porcentagem de germinação.

Mesmo nos tratamentos com maior porcentagem e velocidade de germinação, os valores obtidos são pequenos devido à dormência dos aquênios. Analisando-se pelo aspecto ecológico, em espécies não domesticadas, como no caso da arnica, a germinação das sementes no tempo é uma estratégia de perpetuação da espécie para adaptação e tolerância às adversidades ambientais (MARCOS FILHO, 2005).

Com a desuniformidade no florescimento e consequentemente na maturação dos aquê- nios, bem como a posição dos aquênios nos subcapítulos, capítulos ou planta-mãe, é possível haver distintos graus de dormência entre os aquênios, e, embora o fenômeno de polimorfismo ainda não seja compreendido, observa-se, em espécies da família Asteraceae, que a posição dos aquênios nos capítulos ou na planta-mãe durante 0 amadurecimento pode afetar 0 grau de dormência (BRYANT, 1989).

Ainda em relação à baixa germinação encontrada no ensaio, é importante ressaltar que, pela radiografia obtida antes da montagem do teste de germinação, cerca de $60 \%$ dos aquênios estavam vazios; assim, a porcentagem de germinação real, calculada com base nos aquênios cheios, seria maior que os valores apresentados anteriormente. Na Tabela 2, por exemplo, a germinação para os aquênios sem papus interno na temperatura alternada de 20-30 ${ }^{\circ} \mathrm{C}$, independentemente da incidência de luz, seria de $18,76 \%$, e não de 7,88\%, como apresentado. Em espécies da família Asteraceae, como a arnica, a baixa germinação pode ser atribuída ao alto percentual de aquênios chochos (SASSAKI et al., 1999) ou inférteis (VELTEN \& GARCIA, 2005).

Observou-se que, de modo geral, na temperatura de $20-30 \stackrel{\circ}{\circ}$ alternada, houve significativamente maior porcentagem de germinação em relação às temperaturas mais baixas, principalmente na ausência de luz (Tabela 3).

Tabela3 - Porcentagem de germinação de aquênios de arnica (Lychnophora pinaster Mart.), na presença e na ausência de luz, submetidos a cinco temperaturas. Arnica seed germination (Lychnophora pinaster Mart.), with or without light, submitted to five temperatures.

\begin{tabular}{ccc}
\hline Temperatura & \multicolumn{3}{c}{${ }^{\circ}$ Incidência de luz } \\
\cline { 2 - 3 }$\left({ }^{\circ}\right)$ & Ausente & Presente \\
\hline 15 & $0,13 \mathrm{~b} \mathrm{~B}$ & $2,75 \mathrm{c} \mathrm{A}$ \\
20 & $0,50 \mathrm{~b} \mathrm{~B}$ & $2,88 \mathrm{bc} \mathrm{A}$ \\
25 & $0,13 \mathrm{~b} \mathrm{~B}$ & $4,00 \mathrm{abc} \mathrm{A}$ \\
30 & $0,38 \mathrm{~b} \mathrm{~B}$ & $6,13 \mathrm{ab} \mathrm{A}$ \\
$20-30$ & $4,38 \mathrm{aA}$ & $6,13 \mathrm{aA}$ \\
\hline \multicolumn{3}{c}{$0,1195 \mathrm{~A}$} \\
\hline Média & 'Índice de velocidade de germinação \\
\hline Médias seguidas pela mesma letra, minúscula na coluna e maiúscula na linha, não diferem estatisticamente \\
entre si, pelo teste de Tukey e de $\mathrm{F}$, respectivamente, a 5\% de probabilidade.
\end{tabular}


A incidência de luz possibilitou maior porcentagem de germinação quando as sementes foram submetidas às temperaturas constantes, enquanto para temperatura alternada, não houve diferença significativa entre com e sem luz. Assim, constata-se que a luz teve um papel indutor e/ou catalisador na germinação dos aquênios em temperaturas contínuas; porém, quando alternada, os aquênios foram menos responsivos a este estímulo. Provavelmente, a alternância de temperaturas contribuiu para a superação parcial da dormência do lote de sementes estudado, aumentando o número de sementes germinadas e a aceleração da germinação. Existem espécies nas quais os efeitos da luz e da variação de temperatura são somatórios (BRYANT, 1989).

Observou-se, ainda, que a incidência da luz possibilitou, significativamente, maior velocidade de germinação em relação ao tratamento sem luz. Baseado nos resultados de porcenta- gem e velocidade de germinação, constatou-se que os aquênios de arnica tểm a germinação estimulada pela luz, sendo classificada como fotoblástica positiva preferencial. É importante ressaltar que foram utilizadas 12 horas de luz na simulação da condição natural de campo com temperatura alternada $20-30 \stackrel{\circ}{-}$.

$\mathrm{Na}$ superação da dormência das sementes de arnica, a alternância de temperaturas e a presença de luz parecem ter efeito sinérgico, aumentando a porcentagem de germinação dos aquênios. É provável que as sensibilidades à luz e à temperatura alternada, apresentada pelos aquênios, estejam relacionadas com a adaptação da planta à intensa insolação e com a amplitude térmica, comuns nos campos rupestres, hábitat de ocorrência natural desta espécie.

Os aquênios de arnica apresentam germinação do tipo epígea, conforme se observa na Figura 1.
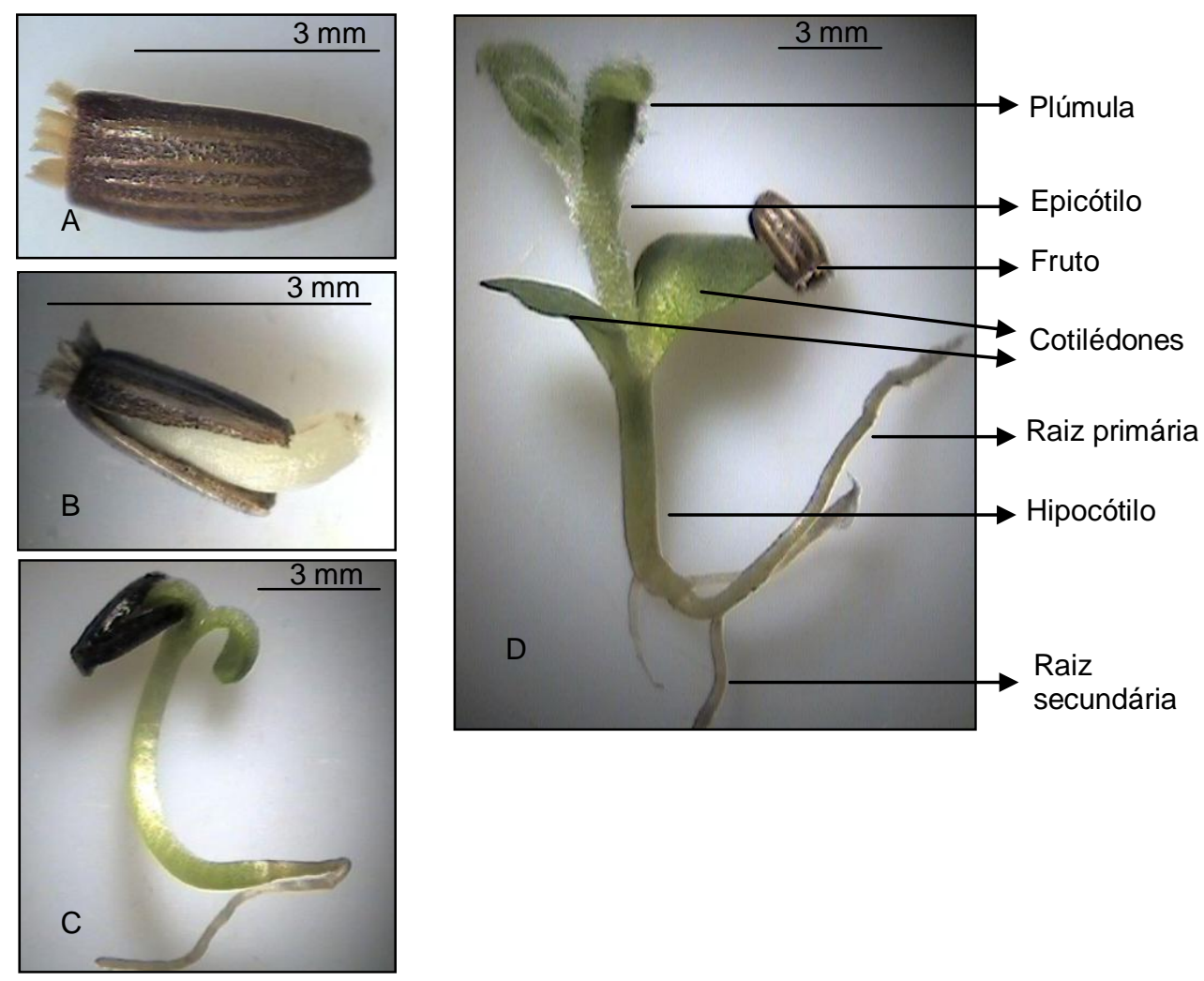

Figura1 - Aquênios e plântulas de arnica (Lychnophora pinaster Mart.. A) Aquênio; B) Emissão da raiz primária; C) Cotilédones e hipocótilo; D) Plântula de arnica (Lychnophora pinaster Mart.). Achenes and seedling of arnica (Lychnophora pinaster Mart.). A) Achenes; B) Root protrusion; C) Cotyledon and hypocotyl; D) Seedling of arnica (Lychnophora pinaster Mart.).

\section{Conclusões}

O estádio de maturação adequado para colheita de frutos e/ou sementes de arnica está relacionado à ausência de papus interno nos aquênios.
As sementes de arnica são fotoblásticas positivas preferenciais, onde a incidência de luz afeta positivamente a germinação em temperaturas constantes. 


\section{Referências}

AZEVEDO, C. F.; BRUNO, R. L. A.; GONÇALVES, E. P.; QUIRINO, Z. G. M. Germinação de sementes de cabaça emdiferentes substratos e temperaturas. Revista Brasileira de Ciências Agrárias, Recife, v.5, n.3, p.354-357, 2010. Disponível em:

<http://www.agraria.pro.br/sistema/index.php?journ al=agraria\&page=article\&op=view\&path $\% 5 \mathrm{~B} \% 5 \mathrm{D}=$ agraria_v5i3a718\&path\%5B\%5D=760>. Acesso em: 11 jun. 2013.

BERGO, C. L.; SILVA, R. C.; OHLSON, O. C.; BIASI, L. A.; PANOBIANCO, M. Luz e temperatura na germinação de sementes de pimenta longa (Piper hispidinervum) e pimenta-de-macaco (Piper aduncum). Revista Brasileira de Sementes, Viçosa, MG, v.32, n.3, p.170-176, 2010. Disponível em:

<http://www.scielo.br/pdf/rbs/v32n3/v32n3a19.pdf>. Acesso em: 11 jun. 2013.

BEWLEY, J. D.; BLACK, M. Seeds: physiology of development and germination. $2^{\text {nd }}$ ed. New York: Plenum Press, 1994. 445p.

BRASIL. Ministério da Agricultura, Pecuária e Abastecimento. Regras para análise de sementes. Brasília: Mapa/ACS, 2009. 399p. Disponível em: <http://www.scielo.br/pdf/rbbio/v59n2/v59n2a 10.pdf>. Acesso em: 11 jun. 2013.

BRYANT, J. A. Fisiologia da semente. São Paulo: EPU, 1989. 86p.

CARVALHO, N. M.; NAKAGAWA, J. Sementes: ciência, tecnologia e produção. 5.ed. Jaboticabal: FUNEP, 2012. 590p.

FERREIRA, D. F. Análises estatísticas por meio do SISVAR para Windows ${ }^{\circledR}$ versão 4.0. In: REUNIÃO ANUAL DA REGIÃO BRASILEIRA DA SOCIEDADE INTERNACIONAL DE BIOMETRIA, 45., 2000, São Carlos, SP. Programas e Resumos... São Carlos: UFSCAR, 2000. p.235.

KLEIN, A.; FELIPPE, G. M. Efeito da luz na germinação de sementes de ervas invasoras. Pesquisa Agropecuária Brasileira, Brasília, v.26, n.7, p.955-966, 1991.

LABOURIAU, L. G. Capacidade e velocidade de germinação. In: LABOURIAU, L.G. A germinação das sementes. Washington: OEA, 1983. p.45-62.

MAGUIRE, J. D. Speed of germination aid in selection and evaluation for seedling and vigour. Crop Science, Madison, v.2, n.2, p.176-177,1962.

MARCOS FILHO, J. Fisiologia de sementes de plantas cultivadas. Piracicaba: FEALQ, 2005. $495 p$.
MELO, P. R. B.; OLIVEIRA, J. A.; CARVALHO, M. L. M.; GUIMARAES, R. M.; CARVALHO, B. O. Aplicação do teste de raios $X$ no estudo da morfologia interna e da qualidade fisiológica de aquênios de arnica (Lychnophora pinaster Mart.). Revista Brasileira de Sementes, Viçosa, MG, v.31, n.2, p.146-154, 2009. Disponível em: $<$ http://www.scielo.br/scielo.php?pid=S0101$31222009000200017 \&$ script=sci_arttext $>$. Acesso em: 11 jun. 2013.

MELO, P. R. B.; OlIVEIRA, J. A.; PINTO, J. E. B. P.; CASTRO, E. M.; VIEIRA, A. R.; EVANGELISTA, J. R. E. Germinação de aquênios de arnica (Lychnophora pinaster Mart.) armazenados em diferentes condições. Ciência e Agrotecnologia, Lavras, v.31, n.1, p.75-82, 2007. Disponível em:

$<$ http://www.scielo.br/scielo.php?pid=S1413-

0542007000100012\&script=sci_abstract\&tlng=pt>. Acesso em: 14 mar. 2014.

NORONHA, A. VICENT, M.; FELIPPE, G. M. Photocontrol of germination of Cucumis anguria $\mathrm{L}$. Biologia Plantarum, Praha, v.20, n.4, p.281-286, 1978.

RANIERI, B. D.; LANA, T. C.; NEGREIROS, D.; ARAÚJO, L. M.; FERNANDES, G. W. Germinação de sementes de Lavoisiera cordata Cogn. e Lavoisiera francavillana Cogn. (Melastomataceae), espécies simpátricas da Serra do Cipó, Brasil. Acta Botanica Brasilica, São Paulo, v.17, n.4, p.523-530, 2003. Disponível em: <http://www.scielo.br/pdf/abb/v17n4/a05v17n4.pdf> . Acesso em: 11 jun. 2013.

REGO, S. S.; NOGUEIRA, A. C.; KUNIYOSHI, Y. S.; SANTOS, A. F. Germinação de sementes de Blepharocalyx salicifolius $(\mathrm{H}$. B. K.) Berg. em diferentes substratos e condições de temperatura, luz e umidade. Revista Brasileira de Sementes, Viçosa, MG, v.31, n.2, p.212-220, 2009. Disponível em:

<http://www.scielo.br/pdf/rbs/v31n2/v31n2a25.pdf>. Acesso em: 11 jun. 2013.

SASSAKI, R. M.; RONDON, J. N.; ZAIDAN, L. B. P.; FELIPPE, G. M. Germination of seeds from herbaceous plants artificially stored in cerrado soil. Revista Brasileira de Biologia, São Carlos, v.59, n.2, p.271-279, 1999. Disponível em: $<$ http://www.scielo.br/pdf/rbbio/v59n2/v59n2a10.p df>. Acesso em: 11 jun. 2013.

SEMIR, J. Revisão taxonômica de Lychnophora Mart. (Vernoniaceae: Compositae). 1991. $515 f$. Tese (Doutorado em Biologia Vegetal) Universidade de Campinas, Campinas, SP. Disponível em:

$<$ http://www.bibliotecadigital.unicamp.br/document/ ?code=vtls000037627>. Acesso em: 11 jun. 2013. 
SILVA, S. M. P. da. Aspectos da fenologia e da reprodução sexuada da arnica (Lychnophora pinaster Mart.) - Asteraceae. 1994. 45f. Dissertação (Mestrado) - Universidade Federal de Lavras, Lavras, 1994.

SOCIEDADE BOTÂNICA DO BRASIL. Centuria Plantarum Brasiliensium Existintionis Minitata. Brasília, DF, 1992. 167p.

SOUZA, A. V.; PINTO, J. E. B. P.; BERTOLUCCI, S. K. V.; CORRÊA, R. M.; CASTRO, E. M. Germinação de embriões e multiplicação in vitro de Lychnophora pinaster Mart. Ciência e Agrotecnologia, Lavras, p.1532-1538, 2003. Edição Especial. Disponível em: $<$ http://sumarios.org/sites/default/files/pdfs/36197_ 4551.PDF>. Acesso em: 11 jun. 2013.

SOUZA, A. V.; PINTO, J. E. B. P.; BERTOLUCCI, S. K. V. TEIXEIRA, R. N. Enraizamento in vitro de plântulas de arnica (Lychnophora pinaster Mart.), uma planta medicinal. Revista Brasileira de Plantas Medicinais, Botucatu, v.7, n.1, p.86-91, 2004.
VELTEN, S. B.; GARCIA, Q. S. Efeitos da luz e da temperatura na germinação de sementes de Eremanthus (Asteraceae), ocorrentes na Serra do Cipó, MG, Brasil. Acta Botanica Brasilica, São Paulo, v.19, n.4, p.753-761, 2005. Disponível em: <http://www.scielo.br/pdf/abb/v19n4/a10v19n4.pdf >. Acesso em: 11 jun. 2013.

YAMASHITA, O. M.; ALBUQUERQUE, M. C. F.; GUIMARÃES, S. C.; SILVA, J. L.; CARVALHO, M. A. C. Influência da temperatura e da luz na germinação de sementes de couve-cravinho (Porophyllum ruderale (Jacq.) Cass). Revista Brasileira de Sementes, Viçosa, MG, v.30, n.3, p.202-206, 2008. Disponível em: <http://www.scielo.br/pdf/rbs/v30n3/27.pdf>. Acesso em: 11 jun. 2013. 